\title{
Fermented Noni Exudate-treated dendritic cells directly stimulate B lymphocyte proliferation and differentiation
}

\author{
XINHAI ZHANG ${ }^{1}$, JINHUA LI ${ }^{1}$, DESMOND K.W. WONG ${ }^{2}$, THOMAS E. WAGNER ${ }^{1,3}$ and YANZHANG WEI ${ }^{1,3}$ \\ ${ }^{1}$ Oncology Research Institute of Greenville Hospital System University Medical Center, Greenville, SC; \\ ${ }^{2}$ Department of Alternative and Complementary Medicine in the John Burns School of Medicine, \\ University of Hawaii, Manoa, HI; ${ }^{3}$ Department of Biological Sciences of Clemson University, Clemson, SC, USA
}

Received December 9, 2008; Accepted February 4, 2009

DOI: 10.3892/or_00000334

\begin{abstract}
Noni juice as a folk medicine has been used for over two thousand years. Recently, some active ingredients of Noni juice have been successfully isolated and intensively studied. Because dendritic cells (DCs) are central regulators both in priming innate and adaptive immune responses and in maintaining self tolerance, in the current study we treated DCs with fermented Noni Exudate (fNE) in order to explore their function in regulating other immune cells. It was shown that fNE-treated DCs stimulate proliferation of splenocytes, among which, B cells are the major responsive cell group. The proliferative response of B cells to fNE-treated DCs is cell contact-dependent, CD40L-independent; and the adhesion feature of DCs was enhanced to form large DC-B conjugation cluster. Moreover, it was demonstrated that fNE-treated DCs promote B cell differentiation and Ig class switching. These results lay a foundation for the further exploration of $\mathrm{fNE}$ as a biological response modifier in the immune system.
\end{abstract}

\section{Introduction}

Morinda citrifolia L. (Rubiaceae), known as 'Noni', is a small tree that grows widely across Polynesia. The roots, barks, stems, leaves and fruits have been used traditionally as a folk medicine for the treatment of many diseases. According to traditional lore and previous scientific research, Noni plant has a broad range of therapeutic effects, including anti-bacterial, anti-viral, anti-fungal, anti-tumor, anthelmintic, analgesic, hypotensive, anti-inflammatory and immune enhancing effects $(1,2)$. In addition, Noni juice was subjected to an official safety evaluation by the European Union and found to be acceptable for human consumption (3). Much research has been done in isolating the active gradients in Noni, as well as understanding

Correspondence to: Dr Yanzhang Wei, Oncology Research Institute, 900 W. Faris Road, Greenville, SC 29605, USA

E-mail: ywei@ghs.org

Key words: Noni, fermented Noni Exudate, dendritic cells, B cells, proliferation its underlying mechanisms. It was found that Noni juice given as a daily intraperitoneal injection significantly increased the lifespan of mice implanted with Lewis lung carcinoma cells. This anti-tumor activity was found to be related to a polysaccharide-rich substance (Noni-ppt) $(2,4)$. Further research demonstrated that Noni-ppt was capable of stimulating the release of cytokines, such as TNF- $\alpha$, IL-1b, IL-12, IFN- $\gamma$ and IL-10 from murine effector cells, but suppressing the release of IL-4 production. Noni-ppt did not show any effects on IL-2 production. Therefore, Noni-ppt appears to stimulate a Th1 cell-mediated immune response while suppressing the Th2 humoral response in mediating its anti-tumor effect (5). It was also demonstrated that Damnacanthal (Dam), a component of Noni root, inhibits viral protein $\mathrm{R}$ (Vpr) induced cell death and, therefore, has potential anti-virus therapeutic effects (6).

Dendritic cells (DCs) are central regulators both in the priming of innate and adaptive immune responses and in maintaining self-tolerance (7). In fact, DCs, when loaded with antigens, are potential candidates for therapies in different diseases, including cancer (8), infection (9) and autoimmune diseases (10). For example, DCs pulsed with $\alpha$-galactosylceramide ( $\alpha$-GalCer), a glyco-sphingolipid originally isolated from a marine sponge, effectively activate natural killer $\mathrm{T}$ cells (NKT) and show strong anti-tumor and anti-infection activities (11-14). Meanwhile, studies in our laboratory have shown that the in vivo delivery of fermented Noni Exudate (fNE), a special preparation of Noni juice, not only effectively render mice resistant to tumor challenge but also eradicate existing tumors (15). In the present study, we investigated whether fNE-treated DCs are able to directly regulate immune cells.

\section{Materials and methods}

fNE. Very ripe Noni fruits were collected from Kawaihae on Hawaii's South Kohala coast. After removing the stems, cleaning thoroughly with a dilute solution of dish washing liquid in tap water using a soft brush, and rinsing completely with deionized water, the fruits were placed in clean and dry stainless steel colanders to drain off the excess water before being placed in coolers for fermentation at temperatures between $24-30^{\circ} \mathrm{C}$ and humidity between $45-55 \%$. After 14 days of fermentation, the liquid exudate from the fruits was collected 
in plastic bottles and frozen at $-20^{\circ} \mathrm{C}$ for storage. Before using, the fNE was thawed to room temperature and adjusted to pH 7.4 with $10 \mathrm{~N} \mathrm{NaOH}$. The juice was then centrifuged at 3,000 rpm for $10 \mathrm{~min}$; and the supernatant was collected and sterilized by filtration through a $0.22 \mu \mathrm{m}$ membrane (Corning Incorporated, NY). Endotoxin-free fNE was prepared using the Detoxi-Gel Endotoxin Removing columns (Pierce Biotechnology, Rockford, IL) according to the product instructions.

Mice and cells. Six- to eight-week-old female C57BL/6J mice from the Jackson Laboratory were maintained in pathogen-free animal facilities. DCs were cultured as previously described (16). Briefly, bone marrow was flushed from the femurs and humerus of mice and passed through $40 \mu \mathrm{m}$ Nylon cell strainers (BD Biosciences, Bedford, MA). After removing RBCs by lysis with ACK lysing buffer (Lonza, Walkersville, $\mathrm{MD})$, the remaining cells were resuspended in DC medium: RPMI-1640 (Cellgro Mediatech Inc, Herndon, VA), 10\% FBS (HyClone, Thermo Fisher Scientific Inc, UT), $50 \mu \mathrm{g} / \mathrm{ml}$ gentamicin (Gibco BRL) and $20 \mathrm{ng} / \mathrm{ml} \mathrm{rmGM-CSF} \mathrm{(Sigma,}$ St. Louis, MO) and seeded into $100-\mathrm{mm}$ non-coated petri dishes at a concentration of $2 \times 10^{6}$ cells $/ \mathrm{ml}$ (10 ml per dish). At day 3, $10 \mathrm{ml}$ fresh DC medium was added to each dish. DCs are matured by adding $100 \mathrm{ng} / \mathrm{ml}$ LPS (Sigma) into the medium and culturing for $24 \mathrm{~h}$. fNE-treated DCs were obtained by adding $\mathrm{fNE}$ at different concentration into $\mathrm{DC}$ medium and incubating for 1 to 4 days before proliferation assay.

Splenocytes were obtained from spleens of mice. B cells, $\mathrm{CD}^{+} \mathrm{T}$ cells and $\mathrm{CD} 8^{+} \mathrm{T}$ cells were purified from splenocytes using dynal negative isolation kits (Invitrogen Co., Carlsbad, CA). NK cells were purified from splenocytes using a MACS NK cell isolation kit (Miltenyi Biotec GmbH, Germany). The purity of the isolated cells was $>90 \%$ as determined by FACS analysis.

Proliferation assay. Twenty thousand or $4 \times 10^{4}$ DCs were co-cultured with $2 \times 10^{5}$ splenocytes, B, CD4 ${ }^{+} \mathrm{T}, \mathrm{CD} 8^{+} \mathrm{T}$, or NK cells in a final volume of $100 \mu 1$ RPMI-1640 culture medium in 96-well round bottom plates for 3 to 8 days. Sixteen hours before the end of culture, $1 \mu \mathrm{Ci}$ [methyl- ${ }^{3} \mathrm{H}$ ]thymidine (GE Healthcare, Piscataway, $\mathrm{NJ}$ ) was added to each well. Cell proliferation was assayed by using a $\left[{ }^{3} \mathrm{H}\right]$-thymidine uptake assay kit (GE Healthcare) and counting with a 1450 Microbeta Trilux Liquid Scintillation \& Luminescence Counter (PerkinElmer, Waltham, MA).

For transwell assays, the BD Falcon 96-multiwell insert system (BD Biosciences) was used. Two hundred thousand B cells were added into the insert, whilst $4 \times 10^{4}$ DCs were added either into the insert (co-culture) or into the well (culture separately). On day 3, $1 \mu \mathrm{Ci}\left[\right.$ methyl- $\left.{ }^{3} \mathrm{H}\right]$-thymidine was added to each insert/well. Sixteen hours later, the cells in the inserts were harvested and analysed for proliferation.

Immunoglobulin quantitative assay. One million splenocytes or B cells per well were co-cultured with an equal number of DCs from different treatment groups in $1 \mathrm{ml}$ of RPMI-1640 culture medium in 24-well plates for two weeks. The concentrations of $\operatorname{IgM}$ and $\mathrm{IgG}$ in the supernatant were determined by using a mouse $\operatorname{IgM} / \operatorname{IgG}$ quantitation ELISA kit (Bethyl Laboratories Inc. Montgomery, TX) following the manual instructions.

Statistical analysis. Each experiment was repeated at least three times and data were triplicated and expressed as arithmetic mean \pm SEM. Levels of significance of the differences between groups were determined by the Student's t-test using the GraphPad Prism 4 software. P-values $<0.05$ were considered statistically significant.

\section{Results}

fNE-treated DCs induce syngeneic splenocyte and B cell proliferation. Kawano et al reported that $\alpha$-GalCer-loaded DCs could selectively stimulate proliferation of syngeneic NKT cell from splenocytes (17). In order to explore if fNE could have a similar bioactivity, LPS-matured DCs were treated with fNE at different concentrations: 10, 4, 2, 1 and $0.1 \%$. After washing three times, fNE-treated DCs were co-cultured with splenocytes at ratios of 1:5 and 1:10 for three days. Compared with regular DCs, fNE-treated DCs had more potential to induce proliferation of splenocytes and the best stimulation occurred when 10 and $4 \%$ fNE were used $(\mathrm{P}<0.001)$. DCs treated with $\mathrm{fNE}$ at as low as $1 \%$ was still able to stimulate splenocyte to proliferate when the splenocyte:DC ratio was 5:1 $(\mathrm{P}<0.05$, Fig. 1A). fNE at a concentration of $4 \%$ was used in all the following experiments.

Since the fNE used in this study contained endotoxins $(0.25 \mu \mathrm{g} / \mathrm{ml}$, unpublished data), we sought to determine whether the proliferation of splenocytes by fNE-treated DCs is due to the endotoxins contained in the fNE. Endotoxin-free fNE was used to treat immature DCs or LPS matured DCs at a concentration of $8 \%$ ( since endotoxin-free fNE was diluted during the purification procedure), which in turn were used to stimulate splenocytes. Although native endotoxin-containing fNE can activate both immature DCs and LPS matured DCs to stimulate splenocyte proliferation, endotoxin-free fNE can only activated LPS matured DC to stimulate splenocyte proliferation (Fig. 1B)

In order to determine which cell type in the splenocytes is the major responder of fNE-treated DC activation, B cells, $\mathrm{CD}^{+} \mathrm{T}$ cells, $\mathrm{CD} 8^{+} \mathrm{T}$ cells and NK cells were separated from splenocytes by using magnetic beads. The cells were then co-cultured with fNE-treated DCs in 5:1 ratio for 3 days. Proliferation assays showed that $\mathrm{B}$ cells were the major responders of fNE-treated DCs $(\mathrm{P}<0.01)$, while $\mathrm{CD}^{+} \mathrm{T}$ cells responded slightly $(\mathrm{P}<0.05) . \mathrm{CD}^{+} \mathrm{T}$ cells or $\mathrm{NK}$ cells did not respond to fNE-treated DCs (Fig. 1C). Both fNE-treated immature DCs and fNE-treated matured DCs can stimulate B cell proliferation (Fig. 1D).

In order to optimize the duration of fNE treatment, DCs were incubated with $4 \%$ fNE for up to 3 days and used to stimulate B cells. The proliferation results showed that although DCs with 1 day incubation with fNE can significantly stimulate $\mathrm{B}$ cells to proliferate $(\mathrm{P}<0.05)$, the best results occurred at 2 and 3 days of fNE incubation ( $P<0.001$, Fig. $2 \mathrm{~A})$. We also optimized the duration of co-culture of fNE-treated DC and B cells. As shown in Fig. 2B, 4 days of co-culture generated the highest $\mathrm{B}$ cell stimulation $(\mathrm{P}<0.001)$ although 3 day co-culture also significantly stimulated B cell 
A

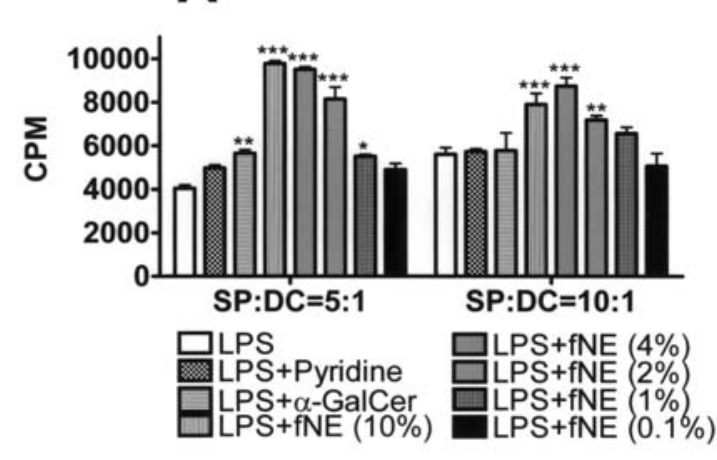

B

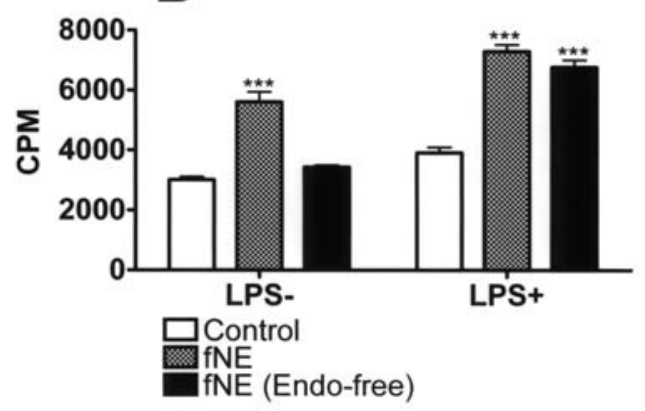

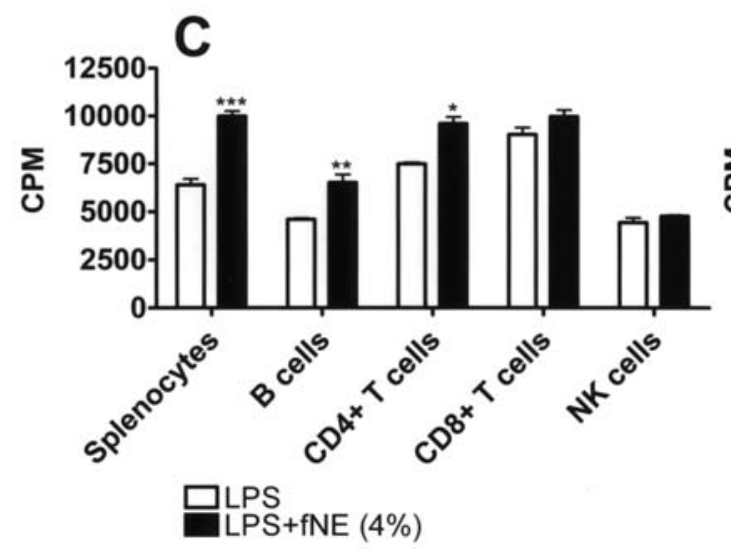

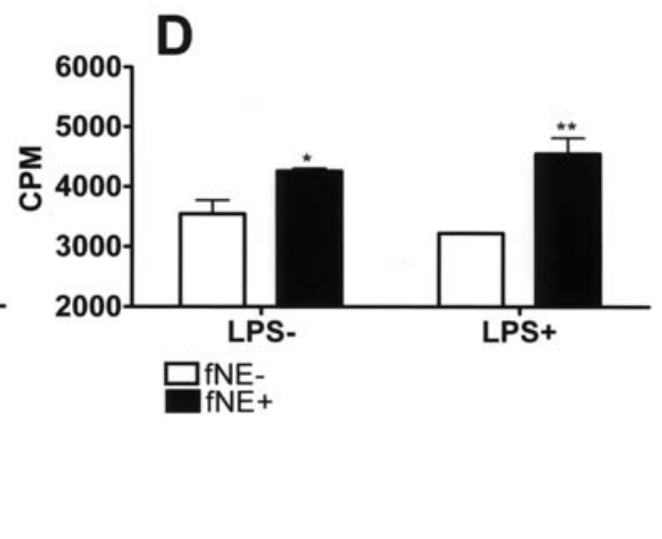

Figure 1. fNE-treated DCs stimulate splenocyte and B cell proliferation. (A) LPS-matured DCs were treated with pyridine, $\alpha$-GalCer, or fNE at indicated concentrations for one day and co-cultured with splenocytes at ratios of 1:5 and 1:10. (B) Immature DCs or LPS matured DCs treated with fNE or endotoxin-free fNE for one day were co-cultured with splenocytes at a ration of 1:5. (C) LPS-matured DCs were treated with 4\% fNE for one day and co-cultured with splenocytes, $\mathrm{B}$ cells, $\mathrm{CD} 4^{+} \mathrm{T}$ cells, $\mathrm{CD} 8^{+} \mathrm{T}$ cells, or NK cells at a ratio of 1:5. (D) Immature DCs or LPS matured DCs were treated with fNE for one day and co-cultured with B cells. After three days co-culture, the proliferation of the cells were analyzed by $\left[{ }^{3} \mathrm{H}\right]$-thymidine incorporation. The data in the graphs represent the summary of three independent experiments with triplicates each time $\left({ }^{*} \mathrm{P}<0.05,{ }^{* *} \mathrm{P}<0.01,{ }^{* * *} \mathrm{P}<0.001\right)$.

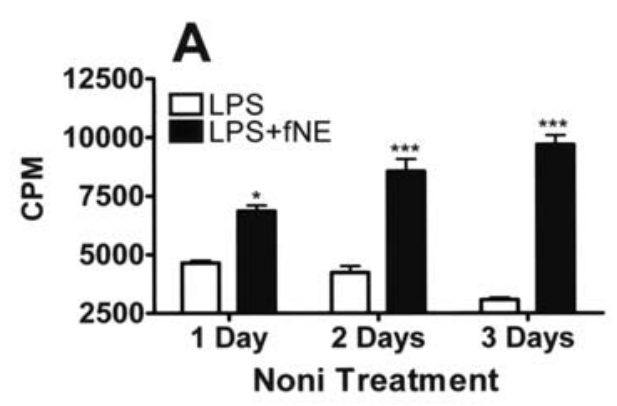

B

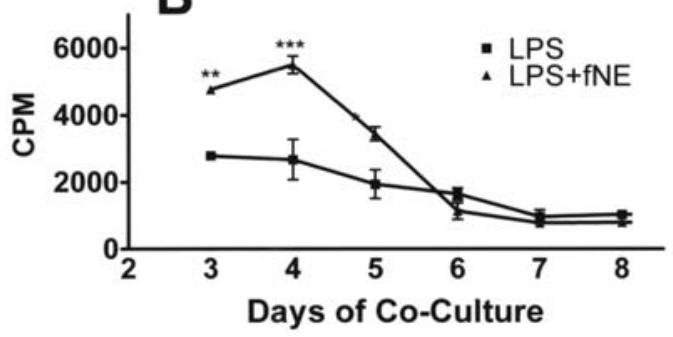

Figure 2. Optimization of fNE treatment and DC/B cell culture. (A) DCs, after maturation with LPS for one day and treatment with 4\% fNE for 1 to 3 days, were co-cultured with B cells at a ratio of 1:5 for three days. (B) DCs, after maturation with LPS for one day and treatment with $4 \%$ fNE for 3 days, were co-cultured with B cells at a ratio of 1:5 for up to 8 days. After co-culture, the proliferation of $\mathrm{B}$ cells was analyzed by $\left[{ }^{3} \mathrm{H}\right]$ thymidine incorporation. The data in the graphs represent the summary of three independent experiments with triplicates each time $\left({ }^{*} \mathrm{P}<0.05,{ }^{* *} \mathrm{P}<0.01,{ }^{* * *} \mathrm{P}<0.001\right)$. proliferation $(\mathrm{P}<0.01)$. These data clearly demonstrate that optimally fNE-treated DCs can directly stimulate purified B cell proliferation.

B cell proliferation stimulated by fNE-treated DCs is CD4OLindependent, and requires cell-cell contact. It has been well established that the CD40L of $\mathrm{T}$ cells is a key molecule for $\mathrm{B}$ cell proliferation and Ig production, especially Ig class switching (18). In order to exclude the possibility that B cell proliferation induced by fNE-treated DCs is due to CD40CD40L interaction from residual T cells in B cell preparation, saturated anti-CD40L monoclonal antibody was used to neutralize CD40L in a DC/B cell co-culture system. The results showed that B cell proliferation stimulated by fNE-treated DCs was not different among the three groups: no isotype antibody, with isotype antibody, and with anti-CD40L antibody (Fig. 3A). In order to rule out the possibility that fNE can directly stimulate $\mathrm{B}$ cells without DC mediation, fNE at different concentrations was added into B cell culture for 4 days, while LPS (100 $\mathrm{ng} / \mathrm{ml}$ ) was added to one group as positive control. The results (Fig. 3B) indicate that fNE alone cannot stimulate B cells.

There are two possible ways that fNE-treated DCs stimulate B cells: fNE treatment may functionally change DCs so that they become activators of $\mathrm{B}$ cells; or the antigen residues from fNE sitting on the surface of DCs may activate the B cells. 

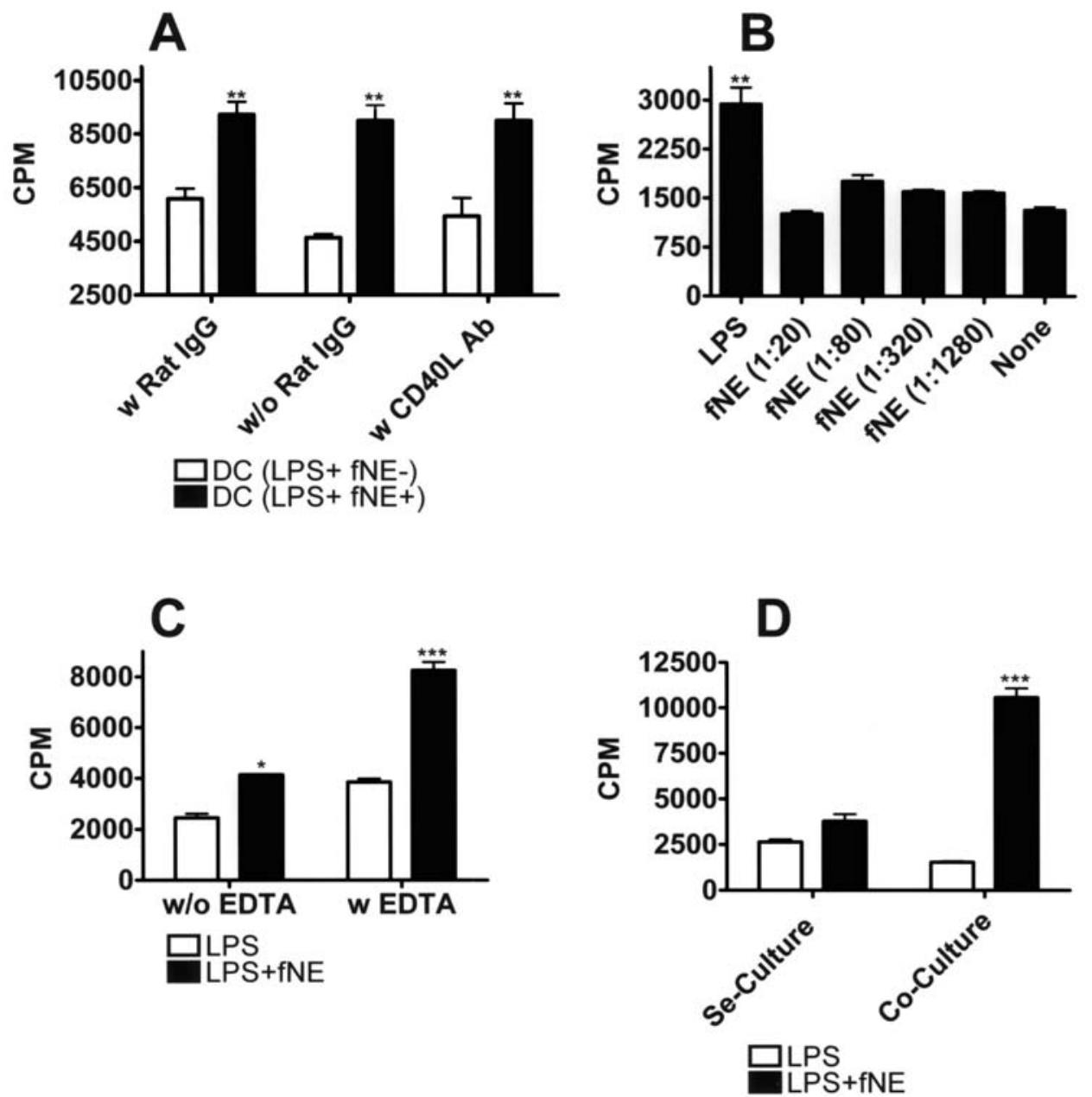

Figure 3. B cell proliferation stimulated by fNE-treated DCs is CD40L-independent and requires cell-cell contact. (A) DCs, after maturation by LPS for one day and treatment with fNE for three days, were incubated with either isotype antibody, or rat anti-mouse CD40L antibody $(0.5 \mu \mathrm{g} / \mathrm{ml})$ for $30 \mathrm{~min}$ before mixed with B cells. (B) LPS or fNE at different concentrations were added directly into B cell culture. (C) DCs, after maturation with LPS for one day and treatment with 4\% fNE for three days, were washed extensively with PBS containing $25 \mathrm{mM}$ EDTA three times before co-culturing with B cells. (D) DCs, after maturation with LPS for one day and treatment with $4 \%$ fNE for three days, were incubated with B cells either in co-culture or in separated culture in the transwell system. DC and B cells were incubated for 4 days and the proliferation of B cells was analyzed by $\left[{ }^{3} \mathrm{H}\right]$-thymidine incorporation. The data in the graphs represent the summary of three independent experiments with triplicates each time $\left({ }^{*} \mathrm{P}<0.05,{ }^{* *} \mathrm{P}<0.01,{ }^{* * *} \mathrm{P}<0.001\right)$.

MacPherson et al reported that washing with EDTA removes all significant retention of antigens on the DC surface (19). We therefore washed fNE-treated DCs extensively with PBS containing $25 \mathrm{mM}$ EDTA before mixing with B cells. Surprisingly, the extensive EDTA wash did not abrogate DC stimulation, but actually enhanced B cell proliferation (Fig. 3C). Finally, we used a transwell culture system to determine if the proliferation induced by fNE-treated DC requires cell-cell contact. In this system, fNE-treated DCs were separated from B cells by the polyethylene terephthalate membrane with $0.1-\mu \mathrm{m}$ pores. As Fig. 3D shows, fNE-treated DCs can only stimulate B cell proliferation by direct cell/cell contract. In summary, the data demonstrated that B cell proliferation stimulated by fNE-treated DCs is cell/cell contact-dependent, CD40L-independent and EDTAresistant; and that free fNE cannot induce B cell proliferation.

fNE treatment does not change the DC key marker expression. In the next step, we wanted to determine if the fNE treatment interferes with key surface marker expression on DCs. DCs treated with or without fNE were stained with FITC-labeled rat anti-mouse CD40, CD80, CD83, CD86, mouse anti-mouse $\mathrm{I}^{-} \mathrm{A}^{\mathrm{b}}$ and PE labelled rat anti-mouse CD154. Compared with DCs without fNE treatment, there was no obvious change in expression of these surface molecules (data not shown).

fNE-treated DCs promote B cell differentiation. As a sign of $\mathrm{B}$ cell differentiation, when fNE-treated DCs were co-cultured with $\mathrm{B}$ cells, large DC/B cell conjugating clusters formed while no clusters were observed with the co-culture of B cells with DCs not treated with fNE (Fig. 4A and B). Furthermore, after two weeks of co-culture, significantly elevated levels of $\operatorname{IgM}$ and $\operatorname{IgG}$ were detected in the supernatant of B cells co-cultured with fNE-treated DCs compared with the coculture of B cells with DCs not treated with fNE $(\mathrm{P}<0.001$, Fig. 4C and D).

\section{Discussion}

In the context of inducing a B cell response, there are two categories of antigens: thymus-dependent (TD) and thymusindependent (TI). TD antigens are proteins or peptides that 


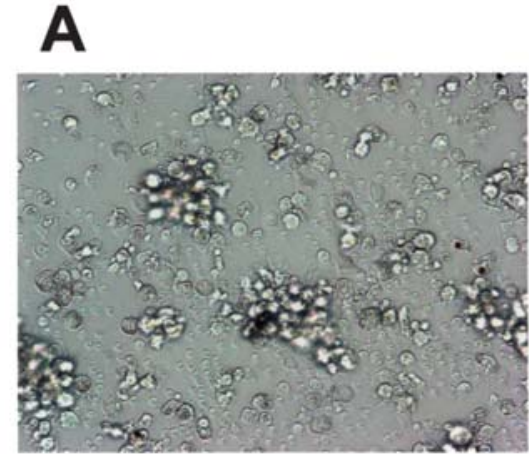

LPS

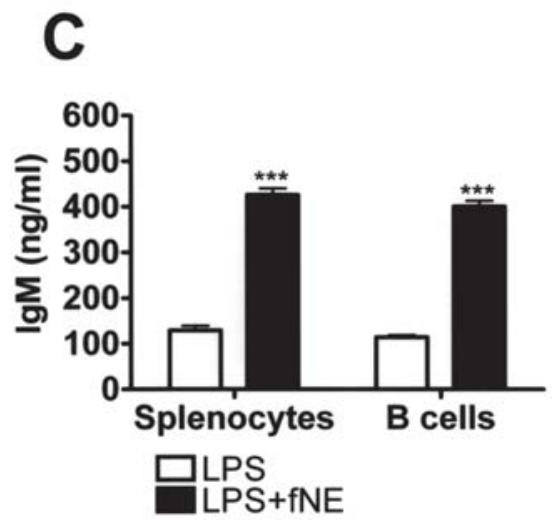

B

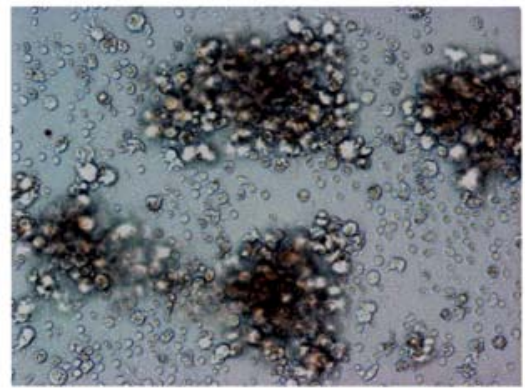

LPS+fNE

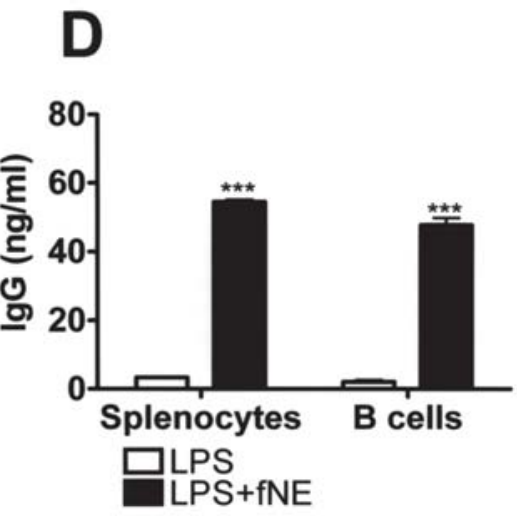

Figure 4. fNE-treated DCs directly stimulate B cell to produce IgG and IgM. DCs, after maturation with LPS for one day and treatment with 4\% fNE for three days, were co-cultured with either splenocytes or B cells at a ratio of 1:5 for two weeks. (A and B) The co-culture three days after incubation. (C and D) Two weeks after co-culture, the supernatant was harvested and analysed for IgM and IgG production. The data in graph represent the summary of three independent experiments with triplicates each time $\left({ }^{* * *} \mathrm{P}<0.001\right)$.

require helper $\mathrm{T}$ cells to elicit an immune response, while TI antigens are generally polysaccharides that do not require $\mathrm{T}$ cell help to elicit an immune response (20). TI antigens are characterized by high molecular weight, repeating epitopes, and slow degradability in vivo. These antigens, such as bacterial capsular polysaccharides, elicit rapid antibody responses by multivalent BCR crosslinking (21). Previous studies also demonstrated that DCs are involved in B cell stimulation by TI antigens (22). B lymphocyte stimulator protein (BLys) and a proliferation-inducing ligand (APRIL) expressed by DCs are known to modulate B cell development, survival, and activation $(23,24)$. In vivo, splenic marginal zone or intestinal lamina propria B cells can communicate with DCs via BLyS and APRIL in a thymus-independent fashion to undergo class switching and produce prompt protection against invading pathogens $(25,26)$. Recently, it was further demonstrated that DCs residing in the bone marrow niche provide a critical cytokine, macrophage migration-inhibitory factor (MIF), to maintain the survival of recirculating B cells in the niche to participate in thymus-independent humoral immune responses to blood-borne microbes $(27,28)$.

Noni has been used medicinally for over two thousand years with a broad range of therapeutic effects, including antipathogen and anti-tumor (2). The high molecular weight fraction of Noni juice is predominantly composed of pectic polysaccharides including $\mathrm{HG}, \mathrm{RG}$ and the neutral side chains of galactan and arabinan. Low levels of AGP are also present along with trace amounts of xyloglucan, heteroxylan and hteromannan. Pectins have been implicated in the immunomodulatory effects of herbal medicines; and it is likely that they are responsible for the effects of Noni-ppt (2). It was previously found that Noni-ppt could activate macrophages, $\mathrm{T}$ cells and NK cells, and stimulate the release of cytokines, such as TNF- $\alpha$, Il-1b, Il-12, IFN- $\gamma$ and IL-10 (5). A study from our lab demonstrated that in vivo delivery of fNE, a special preparation of Noni juice (see Materials and methods), not only renders protection to mice against tumor cells, but also destroys existing tumor cells (15).

In the present study, we explored the biological activity of fNE on DCs. After fNE treatment, both immature DCs and LPS-matured DCs stimulated splenocyte proliferation, among which purified $\mathrm{B}$ cells were the major responsive cell group, while fNE alone could not directly stimulate B cell proliferation. The fact that $\mathrm{fNE}$ contains endotoxin $(0.25 \mu \mathrm{g} / \mathrm{ml})$ could explain why fNE-treated immature DCs are able to stimulate splenocyte and B cell proliferation. The finding that endotoxin-free fNE could still activate LPS matured DC, not immature DCs, to stimulate B cell proliferation suggests that components other than endotoxins in fNE were involved in this bioactivity. The proliferative response of B cells to fNE-treated DCs was cell contactdependent, but CD40L-independent. This agrees with an early finding suggesting that DC-B cell interaction is CD40independent (23). Although the expression of major functional 
DC surface molecules, such as CD80, CD83, CD86 and I-A ${ }^{\mathrm{b}}$ did not change after fNE treatment, the adhesive feature of these DCs was enhanced as evidenced by the large DC-B conjugation clusters observed. The most important finding of this study is that fNE-treated DCs could not only induce B cell proliferation, but also promote its differentiation and Ig class switching. The identification of the active components of fNE for B cell stimulation will not only provide more information on DC-B interaction but could lead to development of therapeutic anti-cancer agents.

\section{Acknowledgements}

We thank Eric Holle and his staff for the professional care of the mice used in this study and Lakendra Workman for her administrative contribution in this study. This study was partially supported by the GHS Oncology Endowment (Y.W., T.E.W.) and the William K. and Frances J. Bryan New Hope Fund for Cancer Research (Y.W., T.E.W.).

\section{References}

1. Akihisa T, Matsumoto K, Tokuda H, Yasukawa K, Seino K, Nakamoto K, Kuninaga H, Suzuki T and Kimura Y: Antiinflammatory and potential cancer chemopreventive constituents of the fruits of Morinda citrifolia (Noni). J Nat Prod 70: 754-757, 2007

2. Bui AKT, Bacic A and Pettolino F: Polysaccharide composition of the fruit juice of Morinda citrifolia (Noni). Phytochemistry 67: 1271-1275, 2006.

3. Palu AK, Kim AH, West BJ, Deng S, Jensen J and White L: The effects of Morinda citrifolia L. (noni) on the immune system: Its molecular mechanisms of action. J Ethnopharmacol 115: 502-506, 2008.

4. Hornick C, Myers A, Sadowska-Krowicka H, Anthony C and Woltering $\mathrm{E}$ : Inhibition of angiogenic initiation and disruption of newly established human vascular networks by juice from Morinda citrifolia (noni). Angiogenesis 6: 143-149, 2003.

5. Eiichi Furusawa AHSSJJ: Antitumour potential of a polysaccharide-rich substance from the fruit juice of $<\mathrm{I}>$ Morinda citrifolia $</ \mathrm{I}>$ (Noni) on sarcoma 180 ascites tumour in mice. Phytother Res 17: 1158-1164, 2003.

6. Kamata M, Wu RP, An DS, Saxe JP, Damoiseaux R, Phelps ME, Huang $J$ and Chen ISY: Cell-based chemical genetic screen identifies damnacanthal as an inhibitor of HIV-1 Vpr induced cell death. Biochem Biophys Res Comm 348: 1101-1106, 2006.

7. Onai N and Manz MG: The STATs on dendritic cell development. Immunity 28: 490-492, 2008

8. Melief CJM and van der Burg SH: Immunotherapy of established (pre)malignant disease by synthetic long peptide vaccines. Nat Rev Cancer 8: 351-360, 2008

9. Torrelles JB, Azad AK, Henning LN, Carlson TK and Schlesinger LS: Role of c-type lectins in mycobacterial infections. Curr Drug Targets 9: 102-112, 2008.

10. Yazawa N, Fujimoto $M$ and Tamaki K: Recent advances on pathogenesis and therapies in systemic sclerosis. Clin Rev Allergy Immunol 33: 107-112, 2007.

11. Silk JD, Salio M, Reddy BG, Shepherd D, Gileadi U, Brown J, Masri SH, Polzella P, Ritter G, Besra GS, Jones EY, Schmidt RR and Cerundolo V: Cutting edge: nonglycosidic CD1d lipid ligands activate human and murine invariant NKT Cells. J Immunol 180: 6452-6456, 2008.
12. Hong $\mathrm{C}$ and Park S-H: Application of natural killer $\mathrm{T}$ cells in antitumor immunotherapy. Crit Rev Immunol 27: 511-525, 2007.

13. Wiethe C, Debus A, Mohrs M, Steinkasserer A, Lutz M and Gessner A: Dendritic cell differentiation state and their interaction with NKT cells determine Th1/Th2 differentiation in the murine model of leishmania major Infection. J Immunol 180: 4371-4381, 2008.

14. Kim S, Lalani S, Parekh VV, Vincent TL, Wu L and Kaer LV: Impact of bacteria on the phenotype, functions, and therapeutic activities of invariant NKT cells in mice. J Clin Invest 118: 2301-2315, 2008

15. Li J, Stickel S, Bouton-Verville H, Burgin KE, Yu X, Wong DKW, Wagner TE and Wei Y: Fermented Noni Exudate (fNE): A mediator between immune system and anti-tumor activity. Oncol Rep 20: 1505-1509, 2008.

16. Lutz MB, Kukutsch N, Ogilvie ALJ, Rössner S, Koch F, Romani N and Schuler G: An advanced culture method for generating large quantities of highly pure dendritic cells from mouse bone marrow. J Immunol Methods 223: 77-92, 1999.

17. Kawano T, Cui J, Koezuka Y, Toura I, Kaneko Y, Motoki K, Ueno H, Nakagawa R, Sato H, Kondo E, Koseki H and Taniguchi M: CD1d-restricted and TCR-mediated activation of V\{alpha\} 14 NKT cells by glycosylceramides. Science 278: 1626-1629, 1997.

18. Kothlow S, Morgenroth I, Tregaskes CA, Kaspers B and Young JR: CD40 ligand supports the long-term maintenance and differentiation of chicken B cells in culture. Dev Comp Immunol 32: 1015-1026, 2008

19. MacPherson G, Kushnir N and Wykes M: Dendritic cells, B cells and the regulation of antibody synthesis. Immunol Rev 172: 325-334, 1999

20. Lesinski GB and Westerink MAJ: Novel vaccine strategies to T-independent antigens. J Microbiol Methods 47: 135-149, 2001.

21. Mond JJ, Lees A and Snapper CM: T cell-independent antigens type 2. Annu Rev Immunol 13: 655-692, 1995.

22. Balázs M, Martin F, Zhou T and Kearney JF: Blood dendritic cells interact with splenic marginal zone B cells to initiate Tindependent immune responses. Immunity 17: 341-352, 2002.

23. MacLennan ICM and Vinuesa CG: Dendritic cells, BAFF and APRIL: Innate players in adaptive antibody responses. Immunity 17: 235-238, 2002.

24. Mackay F, Schneider P, Rennert P and Browning J: BAFF AND APRIL: A tutorial on B cell survival. Annu Rev Immunol 21: 231-264, 2003.

25. Litinskiy MB, Nardelli B, Hilbert DM, He B, Schaffer A, Casali P and Cerutti A: DCs induce CD40-independent immunoglobulin class switching through BLyS and APRIL. Nat Immunol 3: 822-829, 2002.

26. Hardenberg G, van Bostelen L, Hahne M and Medema JP: Thymus-independent class switch recombination is affected by APRIL. Immunol Cell Biol 86: 530-524, 2008.

27. Sapoznikov A, Pewzner-Jung Y, Kalchenko V, Krauthgamer R, Shachar I and Jung S: Perivascular clusters of dendritic cells provide critical survival signals to $\mathrm{B}$ cells in bone marrow niches. Nat Immunol 9: 388-395, 2008.

28. Cariappa A, Mazo IB, Chase C, Shi HN, Liu H, Li Q, Rose H, Leung H, Cherayil BJ, Russell P, von Andrian U and Pillai S: Perisinusoidal $\mathrm{B}$ cells in the bone marrow participate in $\mathrm{T}$ independent responses to blood-borne microbes. Immunity 23: 397-407, 2005. 